\title{
Disability, diversity, and corporate social responsibility: Learning from recognized leaders in inclusion
}

\author{
Robert Gould*, Sarah Parker Harris, Courtney Mullin and Robin Jones \\ Department of Disability and Human Development, University of Illinois at Chicago, Chicago, IL, USA
}

Revised/Accepted March 2019

\begin{abstract}
.
BACKGROUND: Disability is seldom considered a diversity dimension in employer diversity and inclusion strategies. Relatedly, people with disabilities remain underrepresented in the workforce. This exclusion is notable given rising social and political expectations to enhance employment opportunities for people with disabilities.

OBJECTIVE: The authors analyzed factors impacting the integration of disability into organizational practices aimed at recruiting a diverse workforce. The purpose of this synthesis was to develop a descriptive and theoretical mapping of strategies entities use to market their disability inclusion efforts.

METHODS: The research team conducted a content analysis of 34 corporate social responsibility reports from organizations that are nationally recognized for their efforts toward disability inclusion.

RESULTS: Four practices that organizations use to showcase disability inclusion were identified: diversity and inclusion statements, employee resource groups, supplier diversity initiatives, and targeted hiring and recruitment plans. Findings are framed within emerging disability and management theories, as they relate to employee recognition and advancing meaningful inclusion.

CONCLUSIONS: Businesses have not yet prioritized disability within diversity and inclusion reporting and corporate social responsibility strategies. However, as businesses face increased demands for disability inclusion, there will need to be continued research on inclusive practices, organizational culture, and workplace policies.
\end{abstract}

Keywords: Organizational culture, equal opportunity, ADA, hiring, diversity and inclusion

\section{Introduction}

National Disability Employment Awareness Month is celebrated every October to support the inclusion of people with disabilities in the workforce. What started as a weeklong campaign to acknowledge public interest for supporting soldiers with disabilities returning from World War II has grown into an annual event to support a burgeoning workforce of people with disabilities

*Address for correspondence: Robert Gould, PhD, $1640 \mathrm{~W}$. Roosevelt Rd. (MC 626), Chicago, IL 60605, USA. Tel.: +1 312 413 2299; E-mail: Rgould3@uic.edu.
(Office of Disability Employment Policy, 2015). Federal support for inclusion in the workforce is also reflected in U.S. policies such as the Workforce Innovation and Opportunity Act and the Americans with Disabilities Act (ADA). These policies not only reflect federal incentives to increase the labor force of workers with disabilities; they are the bastions of grassroots support for the rights of people with disabilities to access the open labor market (Gould et al., 2015). Moore, McDonald, and Bartlett (2017) find that while policies and federal platforms encouraging employment for people with disabilities influence hiring practices, rising social 
expectations of inclusion are more likely impacting hiring decisions and recruitment strategies.

Support for disability employment now transcends public policy and awareness campaigns. There is increasing pressure to better support people with disabilities in the competitive labor market, where disability inclusion is widely seen as a social imperative. In a national survey, $87 \%$ of customers reported their preference to patron companies that routinely employ people with disabilities (Siperstein, Romano, Mohler, \& Parker, 2006). Furthermore, there is a growing body of evidence about the organizational value of hiring workers with disabilities (C. A. Hernandez, 2018; Kalargyrou, 2014). People with disabilities are a vast and growing segment of the US population, and employees with disabilities may offer specific insight into consumer needs. It is estimated that there are more than 20 million working-age adults with disabilities in the US representing about $\$ 490$ billion in disposable after-tax income (Yin, Shaewitz, Overton, and Smith, 2018). Despite these trends, many people with disabilities remain un or under-employed with only $30.2 \%$ of people with disabilities employed compared to $73.8 \%$ of nondisabled people (Brennan-Curry, 2018). The low employment rate, public policy and social demands, all suggest the need for more innovative strategies to recruit, hire, and retain workers with disabilities.

Theory on how to advance the employment of people with disabilities is not meeting these ongoing social pressures. While disability inclusion is increasingly viewed publicly as a matter of social responsibility, disability is atypically considered in the social responsibility planning of most organizations (Ball, Monaco, Schmeling, Schartz, \& Blanck, 2005). Organizational strategies to foster diversity and inclusion amongst the workforce rarely consider how to support workers with disabilities. Disability is not "high on the diversity radar" of most human resource (HR) professionals or business/management researchers (Chan et al., 2010, p. 116). Given the exclusion of disability from management theory and practice, it is critical to understand how organizations can meet mounting expectations to support workers with disabilities.

This article explores paradigmatic shifts in disability and workplace research to inform discussion and debate about emerging practices used by recognized industry leaders in disability inclusion. The aim is to inform future theoretical and practical inquiry into strategies to foster the workplace inclusion of workers with disabilities by exploring how disability is, and can be, integrated into organizations' social responsibility planning and reporting. We focus on trends related to the integration of disability into social responsibility planning, as trends in research, policy, and practice are positioning disability as an element of diversity in related initiatives. It adds to a small, but growing body of scholarship on organizational strategies and practices that foster disability inclusion (e.g., Beatty, Baldridge, Boehm, Kulkarni, $\&$ Colella, 2018). It includes a review and appraisal of recent research trends impacting disability inclusion in the workplace, and an original synthesis of the rhetorical strategies used by recognized leaders in disability inclusion. The synthesis draws from a multi-staged research project, which includes a content analysis of corporate social responsibility reports from businesses that have received national accolades for their disability inclusion strategies. The intent of reviewing the reports is not to recognize the businesses' initiatives as indicators of best practice, but rather to generate a descriptive and theoretical mapping of the different ways that entities market their disability inclusion efforts. The larger purpose is to better understand how organizations present disability inclusion as part of their commitment to social responsibility. To frame our analysis, we next consider emerging issues related to social responsibility, disability, and human resource practices.

\section{Social responsibility, diversity, and disability}

Social responsibility, also known as corporate social responsibility (CSR), is multifaceted with several different definitions (Fenwick \& Bierema, 2008). It is most often described as the ways that businesses position their organizational policies and conduct activities to positively impact the community (Fenwick \& Bierema, 2008). There is general consensus that CSR initiatives are efforts to align businesses strategies with practices to promote the common good and value of humanity. In practice, notions such as common good and value are imprecise concepts that are tailored to align with company goals and branding.

CSR planning allows businesses to define how they view and respond to social problems, such as the underrepresentation of people with disabilities in the workforce. Businesses share their CSR strategies through reports, web materials, and other publicfacing messages that are reflective of organizational 
culture and priorities. CSR reports provide insight into workplace norms, hiring practices, and overarching aspects of organizational culture (De Stefano, Bagdadli, \& Camuffo, 2018). CSR plans highlight publicly favorable organizational practices, and are used for marketing and recruiting talent (Fenwick \& Bierema, 2008). Diversity initiatives in particular are often crucial aspects of CSR marketing and recruitment as businesses seek to diversify their workforce due to social pressure, increased diversity amongst customer bases, as well as public policies (Moore et al., 2017).

Research on diversity management and CSR can be used to identify organizational practices to attract and support employees from different backgrounds in the workplace. Though there is emergent HR management theory about how diversity strategies impact organizational practices, such discourse rarely includes disability (Gould et al., 2015). Past studies have shown limited attention to disability within CSR and diversity planning. Ball et al. (2005) found that only $42 \%$ of Fortune 100 companies had a diversity policy that expressly included people with disabilities. Diversity plans often shape CSR and organizational culture, and play important roles in decisions to hire, accommodate, and retain workers with disabilities. Schur, Kruse, and Blanck (2005) explore the relationships between corporate culture and the acceptance of people with disabilities by coworkers and management in the workplace. The authors refer to Schein's (2010) conceptions of espoused values, meaning what a company shares publicly as its core beliefs, to argue that companies that are most willing to support workers with disabilities often go out of their way to publicly announce their intention.

\section{Espoused values and disability employment}

Espoused values often reflect a company's priorities in CSR initiatives and internal organizational practices. An espoused commitment to diversity may signify specific goals for hiring and recruitment, formal and informal supports, business strategies, and a number of other factors to support inclusion in the workplace. Despite the growth of diversity management as a best practice, the understanding of disability as a diversity dimension continues to evolve. Some scholars emphasize the importance of including disability in diversity and inclusion man- agement research, but disability is rarely understood as a diverse group in a similar way to other diversity categories (Chan et al., 2010; Theodorakopoulos, \& Budhwar, 2015).

The exclusion of disability from CSR and diversity management theory is indicative of a number of organizational and cultural factors impacting the treatment of workers with disabilities. LengnickHall, Gaunt, and Kulkarni, (2008) interviewed employers regarding hiring practices for people with disabilities and found that many employers did not actively seek out employees with disabilities partially due to negative stereotypes. Chan et al. (2010) found that employers, including HR professionals, commonly hold stigmatizing beliefs about hiring people with disabilities that influence organizational practices. Erickson, von Schrader, Bruyère, and Van Looy (2014) compared survey results from HR professionals regarding barriers to employment for people with disabilities, and found that generally negative attitudes were shown to have decreased over the 13-year timeframe of the study. However, more latent discriminatory beliefs that may discourage disability employment were reported across the study duration. For example, even though equal opportunity laws and policies protect the right to reasonable accommodations, accommodation is commonly misunderstood as special treatment in some workplace settings (Schur et al., 2014). The treatment of workers with disability is shaped by organizational norms and practices; disability is seldom recognized as an employee issue except as a problem to be accommodated when it disrupts standardized processes and procedures.

\section{Advancing disability employment}

The limited attention to disability in theory and practice is particularly concerning because evidence shows that people with disabilities may benefit from better recognition within diversity management initiatives. Research in the field of disability and rehabilitation has primarily focused on individual readiness-commonly referred to as 'supply side' strategies - and overlooked the role of market factors in disability employment (Chan et al., 2010). Karpur, VanLooy, and Bruyère (2014) similarly find that disability employment researchers have primarily focused on workplace accommodation processes or general attitudes toward hiring people with disabilities. The main focus of disability and employment 
research is on opportunities for people with disabilities to become qualified job candidates, or to support rehabilitation professionals in helping people with disabilities obtain and maintain work placements (Chan et al., 2010). Other research has identified factors that influence employers' perceptions of hiring people with disabilities, such as attitudinal barriers and concerns about associated costs of providing accommodations (Chan et al., 2010; Karpur et al., 2014). Research on strategies to advance disability inclusion in the workforce, however, has been limited. There is a growing interest in 'demand side' research, meaning studying business needs and processes, to identify strategies to better support workers with disabilities (Baldridge \& Swift, 2013).

The demand-side focus in disability employment research reflects a growing body of evidence about organizational benefits for hiring workers with disabilities. Commonly reported direct benefits of hiring and accommodating workers with disabilities include lower turnover and productivity (Hernandez \& McDonald, 2010; Kalargyrou, 2014). Additionally, disability can be framed as part of the business case for diversity, which suggests that a more diverse workforce opens up new sources for revenue (Robinson \& Dechant, 1997). Greater gender and racial diversity have been linked to direct monetary benefits for businesses due to expanding customer bases and increasing sales (Herring, 2009). Furthermore, another study found that having LGBT-supportive corporate policies increased firm value, profitability, and productivity (Pichler, Blazovich, Cook, Huston, \& Strawser, 2018) The added value of recruiting employees with disabilities is understudied, but recent evidence suggests a correlation between firm value and hiring employees with disabilities. Hernandez (2018) found that external investors value disability inclusion by studying the market prices of organizations following the day of announcements related to disability discrimination and hiring. Overall, discrimination seems to dissuade investments while disability hiring is positively correlated with firm values.

Little research exists about how organizations actively work to achieve disability inclusion and create workplace opportunities for people with disabilities (Gould et al. 2015; Karpur et al. 2014). One recent systematic review analyzed 88 studies focused on the treatment of people with disabilities in the workplace (Beatty, Baldridge, Boehm, Kulkarni, \& Colella, 2018). Of these studies, 32 were more narrowly focused on organizational aspects as they relate to the workplace treatment of people with disabilitiesbut primarily look at constructs such as managerial and coworker attitudes, and willingness to hire workers with disabilities. Understanding the added value of hiring workers with disabilities is useful to make the business case for disability inclusion. However, many of the identified workplace benefits associated with disability inclusion are intangible and difficult to assign monetary value (Schur et al., 2014). Specific policies and practices to accommodate workers additionally have numerous benefits such as increased productivity of workers with and without disabilities (Solovieva, Dowler, \& Walls, 2011); increased employee morale (Houtenville \& Kalargyrou, 2015); and decreased stress levels, (Schur et al., 2014). In practice, these benefits are difficult to convey and many companies are unaware of the benefits (Houtenville \& Kalargyrou, 2015). The issue is exacerbated by limited knowledge of best practices for supporting and retaining workers with disabilities (Phillips et al. 2016a).

\section{Methods, sampling, and analysis}

To address the aforementioned research gaps, we conducted a content analysis of CSR reports from organizations that have received national recognition for their disability inclusion efforts. The method entails conducting an iterative thematic coding of key reporting narratives (Lieblich, Tuval-Mashiach, \& Zilber, 1998), and deductively framing key concepts within emerging debates around disability employment and diversity. The research questions that guided coding efforts are: (1) What strategies do organizations use to promote diversity and inclusion within their corporate social responsibility reports? (2) And, how do organizations integrate disability into the descriptions of these strategies?

The review process entailed developing a database of the key concepts, quotations, and rhetorical strategies contained within the reports. The three reviewers each conducted a preliminary review of the reports and identified the common strategies used across the report to promote diversity and inclusion (detailed below). The review team convened to reach consensus on the overarching categories, and then extracted key quotations from the reports into the database related to each strategy. For example, as the primary strategy of the reports was including a vision or overarching statement of diversity- diversity statements were copied and pasted directly into the database. 
The research team then convened to systematically categorize the findings, and to conduct a higher order synthesis (i.e., finding meaning across reports) to inform the discussion and limitation sections of this paper.

We analyzed the most recent 2015 and/or 2016 corporate social responsibility reports or equivalent (reflective of the multiple definitions of CSR, some organizations instead titled their reports "sustainability report", "diversity and inclusion report", "impact report", etc.) of the companies that received full points on 2016 US Business Leadership Network (USBLN) Disability Equality Index (DEI) survey. While CSR reporting is not mandatory, it is increasingly done in organizations, often every two to three years. The timeframe was also selected to align with the implementation of the Workforce Innovation and Opportunity Act (WIOA), which was signed by President Obama in July 2014 and began taking effect in July, 2015. WIOA is an important piece of legislation that impacts workforce supports and encourages greater employment for people with disabilities. It is a pinnacle policy that reflects and shapes the social pressures to integrate disability into diversity planning. While this study does not specifically evaluate WIOA, this law provides important context to discuss the impact of public policy on CSR and other business strategies.

USBLN, (rebranded Disability: IN during July 2018 ) is a widely recognized organizational leader in building employer networks to facilitate disability inclusion in the workplace. The DEI is a benchmarking tool for partnering organizations to assess their disability inclusion policies and practices, and organizations with high scores often market their successes. Companies that receive a score of 80 or above on the DEI are listed as the USBLN's Best Places to Work. We chose to only look at reports that score $100 \%$ to limit the sample of the most highly recognized entities in achieving disability inclusion benchmarks. The 2016 DEI scores reflect the initiatives and reporting of industries from the previous fiscal year, which aligns with our selection of reports.

\subsection{Sample}

Our final sample includes the 34 companies that scored $100 \%$ on the DEI and had a public facing social responsibility report (e.g. found on company's website). Reports were located between August 28, 2017-November 1, 2017 by searching on company websites, and through supplementary Google searches using the key words: company name (including acronym variations)+"diversity and inclusion", "corporate social responsibility". Many of the companies had diversity and inclusion webpages that included activities to promote diversity and inclusion, but with the focus of this study on espoused company values - analysis was limited to the activities listed in the CSRs. We excluded eight companies from the sample because they either: 1) did not have a formal report available on their website, 2) the CSR did not specify internal business practices related to diversity and inclusion, and/or 3) the available report was outside of the inclusion timeframe. A complete listing of the reports analyzed, publication date, and company information is included in Appendix A.

Many of the included reports are from global companies, meaning that they operate in multiple countries, though most (88\%) are headquartered in the United States. All of the companies are considered large businesses, with over 4000 employees. More than a quarter of the organizations (9/34) have more than 100,000 employees. Most (30/34) are listed on the Fortune 500. Of the four that were not included in this list, one was a part of the Fortune 1000. The included reports represent companies in 12 different sectors, primarily in healthcare, aerospace and defense, technology, finance and banking, and professional services. See Table 1 below for the full list of all sectors.

\section{Results: Integrating disability into CSR reporting}

We identified ten organizational strategies related to disability in the CSR reports. In this section, we analyze the most prominent features of these strategies to provide a descriptive overview of how

Table 1

Included company sectors corporate social responsibility reports

\begin{tabular}{lcc}
\hline Industry Sector & Frequency & Percentage \\
\hline Healthcare & 6 & $18 \%$ \\
Aerospace \& Defense & 4 & $12 \%$ \\
Technology & 4 & $12 \%$ \\
Finance and banking & 4 & $12 \%$ \\
Professional Services & 4 & $12 \%$ \\
Telecommunications & 3 & $9 \%$ \\
Transportation & 3 & $9 \%$ \\
Energy & 2 & $6 \%$ \\
Food, Beverages \& Tobacco & 1 & $3 \%$ \\
Motor Vehicles \& Parts & 1 & $3 \%$ \\
Household Products & 1 & $3 \%$ \\
Retailing & 1 & $3 \%$ \\
\hline
\end{tabular}


organizations promote disability inclusion within these publications. We focus on four strategies to promote disability inclusion that are commonly discussed in relation to disability: diversity and inclusion statements $(\mathrm{n}=28)$, employee working groups $(\mathrm{n}=23)$, supplier outreach $(\mathrm{n}=14)$, and recruitment and hiring $(\mathrm{n}=10)$. The majority of the commentary specific to disability within these reports pertains to these concepts, and thus is the primary focus of our analysis. Other strategies were commonly discussed across the reports, such as: highlighting awards received related to disability inclusion and philanthropic giving, and community partnerships with disability related organizations. See Table 2 below for a full list of the strategies identified in the reports.

\subsection{Diversity and inclusion statements}

Diversity and inclusion statements often provide a glimpse of overarching organizational commitments, practices, policies, and culture. Public reporting of diversity strategies generally signify top-level management's commitment to implementing diversity and inclusion policies in the workplace (Broughton \& Strebler, 2008). Top-level buy in is thought to be an essential aspect of sustaining and actualizing diversity and inclusion plans (Broughton \& Strebler, 2008) and has been found as contributing factor for disability inclusion specifically in the workplace (Phillips et al., 2016b). While there seems to be growing consensus about the value of visible organizational commitments to diversity, less is known about how these statements vary in theory and in practice, especially as they relate to disability. All of the included reports had sections devoted to diversity, and $28(82 \%)$ of the organizations specifically mentioned disability in the diversity and inclusion section. The remaining six reports did not list different facets of identity in their commitment to diversity and inclusion. Overall, the diversity and inclusion statements can be categorized by three different approaches to disability inclusion: emphasizing the general importance of disability as a facet of diversity; identifying the specific benefit of employees with disabilities; and/or expressing the more universal value of diverse ideas and thought.

Most often, disability is described as one of many aspects of diversity similarly to race, color, religion, national origin, gender, sexual orientation, gender identity, age, physical or mental disability, genetic factors, and military/veteran status. While diversity statements may include other characteristics, these were the most often articulated within the organizational reports. Diversity statements typically state a commitment to promoting equal opportunities and non-discrimination, at times reaffirming the organization's adherence to law such as the ADA (e.g., Boeing, Lincoln Financial Group, and Pacific Gas and Electric). While emerging theory on practices in disability inclusion suggest moving beyond a compliance or legalist framework (Gould et al., 2015), the inclusion of disability still stands out as a notable marker of the businesses that have been recognized in the Disability Equality Index. Compared to past research that has shown limited attention to disability inclusion in diversity planning, such as Ball et al.'s (2005) study that found less than half of the Fortune 100 companies mentioned disability in their plans, the organizations analyzed in this study all rhetorically consider disability within their CSR reporting efforts.

At times, organizations go beyond a general commitment to diversity or culture of inclusion and lay out a plan of how they support different employees. Eight reports describe the unique importance of disability in the workforce. The stated value of

Table 2

Topics identified in corporate social responsibility reports by frequency

\begin{tabular}{lcc}
\hline Strategy & Frequency & Percentage \\
\hline Disability included as part of diversity and inclusion section & 28 & $82 \%$ \\
Disability related employee resource group & 23 & $68 \%$ \\
Highlighting awards received related to disability inclusion & 19 & $56 \%$ \\
Philanthropic giving or community partnerships to disability related organizations & 15 & $44 \%$ \\
Supplier diversity included disability-owned & 14 & $41 \%$ \\
Outreach and/or accommodation for customers with disabilities & 12 & $35 \%$ \\
Targeted recruitment and hiring of people with disabilities & 10 & $29 \%$ \\
Accommodation resources for employees & 7 & $21 \%$ \\
Disability (short- and/or long-term) employee benefits packages & 7 & $21 \%$ \\
Disability related training for employees & 5 & $15 \%$ \\
Capture/report data about number of disabled employees & 5 & $15 \%$ \\
\hline
\end{tabular}


employees with disabilities is described in relation to ingenuity and creating new ideas, such as CSC's (2016) description of building a network of employees with disabilities to "harness innovation" (CSC, p. 21). The importance of workplace diversity is described in relation to leveraging diverse abilities and differences. For example General Motors (2016), Lockheed Martin (2016), and PricewaterhouseCoopers (2016) describe disability as an asset for serving diverse customer bases and for building a team of workers with diverse abilities. One key feature about the reports that describe specific value of workers with disabilities is that they tend to also include more concrete plans about how they retain and support these workers. For example, Ernst and Young, LLP (2015) describe their commitment to accessibility in the workplace through:

"Ongoing investment in professional networks, educational resources and accessible work spaces. This includes providing accessibility to the technologies we build, buy and deploy. Our inclusive culture enables diverse teams to bring different perspectives and points of view that ultimately result in exceptional service for our clients." (p. 31)

The statement contains a deliberate appeal to supporting employees with disabilities and in turn espouses a heightened valuation of such workers.

A third approach to describing diversity was to consider the strength of all employees, regardless of their specific identity. These reports tended to emphasize the meritocratic treatment of all employees, and the value of diverse thinking instead of specific identity related experience. The six reports that did not specifically mention identity groups in their diversity statements largely utilized this strategy. Additionally, some reports mentioned different identity groups including disability, but highlight how their approach extends beyond looking at such categorizations. For example, Walmart's (2016) plan states that inclusion goes "beyond" looking at characteristics such as disability, and also entails "seek [ing] and embrac [ing] differences in people, ideas and experiences," (p. 5). By describing the importance of diversity in terms of ideas rather than identity, the narrative that emerges is one that places values in fairness and equal treatment amongst all employees. Meena and Vanka (2017) emphasize that the perceived fairness of HR decisions, especially in hiring, often helps build organizational buy-in for diversity and inclusion policies and practices.

\subsection{Employer resources groups}

Employee resource groups (ERGs) are ways for people with similar backgrounds to connect and network within a business. Collectively, ERGs seem to serve an important role in the CSR reporting, and are framed as a way to engage people with disabilities, both as customers and employees. In the broader literature, creating disability specific employee groups, such as employee resource and affinity groups, is recognized as a best practice for advancing disability and inclusion in the workplace (Erickson et al., 2014). Twenty-four of the businesses discussed disability resource groups. These groups may differ in names and purpose among different companies, but having a group dedicated for people with disabilities and allies is a common strategy for documenting disability inclusion. ERGs are described in relation to how the member group contributes to supporting workers with disabilities or how the group provides broader social or philanthropic services.

Some organizations describe ERGs as formalized employee affinity groups, similar to groups created for other facets of identity. Affinity groups tend to focus on raising awareness of issues that employees may face in the workplace such as barriers to inclusion, cultural biases, stigma, and obtaining workplace supports. Some groups are discussed alongside services or disability benefits packages offered to employees, and even serve as an internal resource to help facilitate accommodation requests. Mostly, groups are described as spaces for employees with disabilities to discuss workplace issues and to build a more inclusive workplace. Procter \& Gamble (2015) delivers a fairly typical description of an ERG:

"The People with Disabilities (PwD) Employee Group is devoted to raising awareness about issues facing people with disabilities and serving as a change agent to foster a more inclusive work environment for every employee, regardless of mental or physical limitations," (p. 17).

While the statement may not seem overly ground breaking or novel in its mission, the stated commitment to employee issues for people with disabilities is what stands out. When disability employee groups are framed similarly to other affinity groups, it firmly places disability as part of diversity in the same way as race, sex, gender, ethnicity and other facets of identity that are more typically included. 
One major difference in disability employee groups as compared to other ERGs is that disability groups were not all strictly identity based, and often included family members and caregivers of people with disabilities. In fact, six of the reports expressly mention the roles of caregivers, advocates or parents of people with disabilities in employee groups. These descriptions of resource groups tended to focus on philanthropic goals focusing on disability awareness and respect, rather than specific employee or customer benefits. For example, American Airlines' (2016) "Abilities and Bridges Employment Business Resource Group," (p. 11) helps support a simulation of the airport experience for families with autistic children. This reflects a common reporting strategy of highlighting volunteerism and charitable achievements conducted by employees to help community members and customers with disabilities. The unique positioning of disability employee groups as both an employee resource and as charitable is further explored below.

\subsection{Supplier diversity}

Supplier diversity initiatives are often discussed as philanthropic ways of diversifying the workforce. Supplier diversity programs are purchasing initiatives that promote contracting with groups, such as women and ethnic/racial minorities, that have had pronounced difficulty competing against longstanding conglomerates or contractors (Worthington, Ram, Boyal, \& Shah, 2008). Programs that emphasize contracting with historically disenfranchised groups report increased competition and general business advantage from their promotion of social responsibility (Worthington et al., 2008). Ball et al. (2005) found that disability is seldom seen as a supplier diversity category for contracting purposes. In the reviewed CSR reports, however, external collaboration with disability organizations was repeatedly part of making the business-case for disability inclusion. Fourteen of the organizations (41\%) discuss disability in relation to contracting and supplier diversity plans. Supplier diversity is often used to showcase collaboration and partnership with disability-related organizations. For example, six organizations specifically mention their relationship with the USBLN, which provides certification for Disability Owned Businesses, Veteran-Disability Owned Business Enterprises, and Service-Disability Owned Business Enterprises (businesses owned by a veteran who acquired a disability during their time of service) to help with recruiting.
Including disability within supplier diversity plans is a common promotional strategy, but unlike other stated strategies for disability inclusion, the reports contain very little detail on specific accomplishments or contracting processes. Generally, descriptions of supplier diversity plans are limited to a listing of the different groups considered in contracting process and national groups that acted as partners to identify credible contractors. For example, Comcast NBCUniversal's (2016) "supplier diversity team" highlights their work with "not only minority and womenowned businesses, but also veteran, LGBT, and disability-owned businesses," (p. 12). HP Inc. (2015) and Northrup Grumman Corporation (2016) are the only two organizations that provide statistics about how much is spent with diverse suppliers, including Veteran service-disability owned businesses. While the specific recognition of disability as a supplier category of providers is atypical and progressive, providing more concrete examples of inclusive practices workplace inclusion may be more indicative of meaningful inclusion of people with disabilities in the workplace.

\subsection{Targeting hiring and recruitment}

Perhaps the most important indicator of building meaningful inclusion and actualizing a CSR plan is how successful an organization is at hiring individuals with disabilities. Hiring and recruitment plans for employees with disabilities are found in statements about creating a culture of inclusion through a diverse workforce, specific plans for recruitment, and descriptions of workforce training programs. Disability-specific recruitment plans are particularly important for advancing workplace equity and inclusion given accounts of prejudice favoring candidates without disabilities (Kaye, Jans, \& Jones, 2011), and internalized biases that dissuade some applicants with disabilities from applying to many open job searches (Houtenville \& Kalargyrou, 2015). While only 10 organizations $(29 \%)$ specifically included targeted recruitment plans aimed at people with disabilities, all of the reports contained specific sections on diversity and inclusion, and these concepts were often described in relation to their impact on recruitment and hiring decisions.

The business case for recruiting and hiring employees with disabilities often connects these decisions to providing customer service and understanding customer needs. Value is a shared concept across the reports, as organizations frequently discuss the ben- 
efit of hiring in relation to the diverse perspectives of employees, advances related to employees' specific viewpoints, and the specific customer markets that employees with disabilities may serve. For example, groups like Aetna (2015) emphasize the competitive advantage of diversity. The reports often describe benefits for employees and customers, ultimately focusing on the shared impact on the bottom-line of the organization: employees with disabilities provide value in their ability to serve emerging customer bases. General Motors (2016) discusses the tangible benefits of hiring employees with disabilities in the description of their employee resource group dedicated to building disability awareness, that is:

"Focused on building a culture of inclusion that serves customers, employees, and community through innovation, talent enrichment, awareness, and outreach for people with disabilities and their allies. They provide valuable perspectives to the company regarding autonomous vehicle design, facility design and recruiting talent with disabilities." (p. 7)

In this case, the value of hiring people with disabilities and the recognition of disability as part of diversity is directly connected to emerging product development and novel contributions to company interests.

Recognizing new sources of talent and insight motivates employers to diversify the workforce. Employer recruitment plans thus often start with targeted internship and training for students with disabilities. Four included reports described philanthropic training programs for people with disabilities. Targeted recruitment and training programs are used to showcase philanthropic contributions of the organizations and meet the acute need for developing a better-prepared workforce of people with disabilities. Organizations engaging in these activities often highlight the role of training programs as a pathway to employment, such as HighMark Health's (2016) Careers2B program that offer students the opportunity to be hired after completing the program. Generally, organizations described the programs as paid, professional opportunities that included mentoring or other specific training. The emphasis on paid training is especially important as people with disabilities are much less likely to receive payment for their work or internship experiences than their peers without disabilities (Erickson et al., 2014).

One unique approach discussed by Capital One (2015) is a paid-internship program for college stu- dents on the autism spectrum in conjunction with the supports offered to employees with disabilities and caregivers such as a group that: "helps associate members navigate health insurance and financial issues, access insight and research, enable community services, and create a network for emotional support," (p. 20). In this instance, disability recruitment is supplemented with description of specific resources that enhance retention. The bilateral focus on training and workplace supports aligns with bestpractice identified in recent research on disability and employee retention. Interventions and programs to address disability employment gaps tend to focus on individual preparedness and general job skills, rather than identifying specific needs of business entities themselves (Karpur et al., 2014). In turn, employers often describe the inability to recruit adequately prepared employees with disabilities as a barrier to meeting inclusive hiring goals. Overall, the hiring and recruitment plans of these organizations tend to make a business argument for inclusion and detail a number of specific workplace supports.

\section{Discussion}

While the organizations do not provide the detail necessary to suggest a relationship between reporting strategies and ensuing practices, the descriptive differences can be explored more deeply in relation to current research and theory through a synthesis of the findings.

The first key challenge to disability inclusion can be described as the struggle for recognition. Recognition involves the steps that organizations take to acknowledge specific needs or supports for a group of workers. In research on disability inclusion in the workplace, the recognition of employees with disabilities is often seen as a vital part of spearheading a larger organizational commitment to disability inclusion (Schur, Kruse, \& Blanck, 2013). Debates about group recognition in the workplace delineate strategies that focus on creating specialized or tailored support for a group of workers with shared experience versus integrating supports into existing groups and infrastructure (Bickenbach, 2014; Zola, 2005). In disability theory, this debate is often categorized as the difference between specialization and mainstreaming (Bickenbach, 2014). One example of the difference in practice would be to strategize ways to better provide accommodations to workers with disabilities versus universally designing workplaces to mitigate the need for accommodation. 
The differing narratives of CSR in relation to recognition are perhaps most clearly illuminated in the diversity and inclusion statements of the reports. Reports that theorized advances to diversity regardless of specific facets of identity evoke a mainstreaming approach by emphasizing meritocratic treatment, a culture of inclusion, and universal employee benefits. Interestingly, the organizations that framed diversity in this way tended to discuss disability in relation to philanthropic activities, but did not describe specific employee inclusion strategies. Disability specific statements, instead, more readily included specific supports and working groups for employees with disabilities. For example, TD Bank (2016) describes their disability inclusion plans, which entails: "moving beyond just accommodation to apply a number of inclusion best practices that help us build a deeper emotional connection with people with disabilities," (p. 4). While some organizations frame their CSR initiatives as a benefit to all employees, others highlight the specific benefits for certain groups.

Across the reports, organizations mostly highlight their specialization efforts rather than mainstreaming practices. Opportunities for recognition are often built into organizational practice, such as the creation of employee affinity groups and peer-to-peer networks. Employee resource groups are increasingly thought to be important components of building inclusive workplace that are welcoming and attractive to people with disabilities (Erickson et al., 2014). The specialization approach frames issues such as antidiscrimination protections as shared and collective, thus justifying the creation of specific groups for employees with disabilities and even targeted hiring and recruitment initiatives. These groups can be tailored to address employee-specific needs, but also can provide value in organizations that promote 'identity-free' HR practices such as the numerous organizations that frame their diversity initiatives in terms of diverse thoughts rather than group identity.

A push for recognition that focuses on mainstreaming would suggest better integration of disability into existing groups and resources, rather than creating additional or separate supports or groups. Interestingly, mainstreaming strategies, such as highlighting the general accessibility or universal supports for workers are not commonly discussed in these reports. Many organizations make aspirational statements such as building a culture of inclusion, but stop short of naming practices that support the mainstreaming of employees with disabilities.
Research on best practice suggests integrating, or mainstreaming, disability inclusion into existing workforce policies and practice that can benefit all workers as much as possible. Gilbride, Stensrud, Vandergoot, and Golden (2003) found a number of general workforce policies that favor disability inclusion, and benefit all employees as well. For example, flexible scheduling and accommodation practices are thought to advance disability acceptance as they are then less seen as special treatment to people with disabilities. The mainstreaming of disability supports across existing resources and groups is an attractive pathway to advance disability inclusion due to the plurality of experiences amongst workers with disabilities as a group.

The advantage of the mainstreaming approach is that the needs to provide accommodations may be diminished if organizational practices are designed to support all workers. Universalizing certain employee practices that are more typically used to accommodate individuals with disabilities, such as flexible work schedules, may reduce disability stigma where accommodations are often seen as 'special' treatment (Baldridge \& Veiga, 2001; Gilbride et al., 2003). Organization processes that universally benefit employees with and without disabilities are not well documented in these reports or the broader literature on disability inclusion. Future research may consider how disability inclusion is mainstreamed across other organizational practices, and not just through disability-specific groups or resources.

Employee recognition is an important part of building a more diverse workforce. Socially responsible strategies used to support employees with disabilities are described in similar ways to that of other diverse groups. However, simply acknowledging disability as a category within diversity does little to ameliorate the additional barriers to inclusion that many employees with disabilities and their family members face. A second key challenge to advancing disability inclusion is ensuring that opportunities for inclusion are meaningful and sustainable. Perfunctory or 'tokenistic' practices that highlight the success of few specific individuals without addressing larger barriers to inclusion, can be detrimental to creating a welcoming and inclusive workplace (Robert, 2003), and may dis-incentivize recruitment from underrepresented groups. To move beyond such practices, organizations could recognize that many employees benefit from accommodation processes, flexibility for medical leave, and other forms of peer support. 
Even though a number of disability benefits such as employee accommodation programs and peerpeer networks are described in the reports, these organizations are far from typical in terms of CSR and employer practices. Disability continues to be seen as an example of charity, and is seldom recognized as an asset for diversity in the employee base (Shore et al., 2009). Conversely, these organizations frequently make the business case for disability inclusion across different sections of the reports, framing workers with disabilities as important resources to serve an emerging market base (Hernandez, 2018).

To appeal to recruitment efforts of people with disabilities, future descriptions of disability inclusion may benefit from better incorporating emerging best practices for disability inclusion into their CSR reports. For example, describing a specific commitment to workplace accommodations or inclusive practices may attract employee with disabilities. Erickson, von Schrader, Bruyère and VonLooy (2014) compared survey results from HR professionals regarding barriers to employment for people with disabilities, and found that one of the most effective employer practices for retaining workers with disabilities is to create a centralized accommodation fund specifically designated for ongoing support needs. Similarly, Markel and Barclay (2009) identified a number of strategies that companies use to attract and support people with disabilities, including: managerial training opportunities for management, inclusive and/or targeted recruiting practices, and investing in universal design for the physical space of the workplace. Highlighting these practices are important ways for companies to leverage their espoused values to build inclusive cultures.

\section{Limitations}

As previously noted, evidence of the difference between organizational practices and reporting efforts is largely discursive, although the accounts may be indicative of variations in how companies actualize their diversity goals. Social desirability bias likely impacts organizational rhetoric where businesses may frame their initiatives to match cultural expectation and to suggest adherence with civil rights laws (Kaye et al., 2011). There is a pronounced difficulty in documenting organizational factors related to disability inclusion, as entities often overstate their efforts, and others may be reluctant to admit noncompliance (Gould et al., 2015).
Another limitation of this study is the inability to disaggregate findings according to disability types, as disability is often considered as a relatively homogenous group in much of the existing scholarship and organization reporting efforts. A similar limitation was noted in the recent systematic review conducted by Beatty et al. (2018) where existing data prevents the analysis of nuances and variability within disability identities. The limited data available from CSR reports largely considers disability as an overarching and homogenous group, and does not reflect on the numerous differences of experiences related to impairment, cultural background, race, class, and other facets of identity. HR researchers and practitioners have barely breached the surface in considering the complexity of disability as an intersectional facet of identity, which suggests the needs for future inquiry into this area.

The critical synthesis of organizational reporting should thus not be understood as an analysis into the efficacy of the organizations' practices, but rather as a descriptive and theoretical interpretation of how disability inclusion is framed within CSR reports. The limited reporting or detailed description such as successful hiring outcomes, however, may be indicative of a larger implementation problem in disability inclusion efforts. Karpur et al. (2014) highlighted the larger "knowing-doing gap" of HR professionals, which means that while the organizations may receive information about desirable practices, they "lack the tools and capacity to implement new practices" (p. 235). Although these organizations are widely recognized for their leadership in disability inclusion, the public reporting efforts provide limited evidence of actualizing commitments to disability inclusion beyond the rhetoric. Future research may delve deeper into the implementation process and effective practices.

\section{Conclusions}

There are numerous complexities in creating policies and practices to best support employees with disabilities. A strength of these organizational reports is how they broadcast their culture of inclusion and ultimately value employers with disabilities for their ability to work with an emerging customer base. Even if these practices are mainstreamed into an organization's culture, people with disabilities often experience material disadvantage that require additional organizational strategizing. While reasonable 
accommodations are protected workplace processes for employees with disabilities, the costs of assistive technology, device, and supports, often falls on the individual. Organizations may strive to advance disability inclusion as part of broader diversity initiatives, but also may need to create policies to better accommodate and support workers with disabilities. Disability is not yet a priority issue for diversity and inclusion reporting and CSR initiatives. More recent interest in disability inclusion is being driven by political demand, as well as an increased recognition of the importance of serving diverse markets. As demand for disability inclusion increases, better understanding of inclusive practices, organizational culture, workplace policies and processes will help businesses with their diversity efforts and support meaningful inclusion of people with disabilities.

\section{Acknowledgments}

This research is funded by the Administration for Community Living, National Institute on Disability, Independent Living, and Rehabilitation Research (NIDILLR), Grant Number 90DP0091-02-00.

\section{Conflict of interest}

None to report.

\section{References}

Baldridge, D. C., \& Swift, M. L. (2013). Withholding requests for disability accommodation: The role of individual differences and disability attributes. Journal of Management, 39(3), 743762. https://doi.org/10.1177/0149206310396375

Baldridge, D. C., \& Veiga, J. F. (2001). Toward a greater understanding of the willingness to request an accommodation: Can requesters' beliefs disable the Americans with Disabilities Act? Academy of Management Review, 26(1), 85-99. https://doi.org/10.5465/amr.2001.4011956

Ball, P., Monaco, G., Schmeling, J., Schartz, H., \& Blanck, P. (2005). Disability as diversity in Fortune 100 companies. Behavioral Sciences \& the Law, 23(1), 97-121. https://doi.org/10.1002/bsl.629

Beatty, J. E., Baldridge, D. C., Boehm, S. A., Kulkarni, M., \& Colella, A. J. (2018). On the treatment of persons with disabilities in organizations: A review and research agenda. Human Resource Management. https://doi.org/10.1002/hrm.21940

Bickenbach, J. (2014). Universally design social policy: When disability disappears? Disability and rehabilitation, 36(16), 1320-1327. https://doi.org/10.3109/09638288.2014.932447
Brennan-Curry, A. (2018). nTIDE August 2018 jobs report: Return to positive trend for employment of Americans with disabilities. Employment Policy and Measurement Rehabilitation and Research Training Center. Retrieved from https://researchondisability.org/epm-rrtc/epmnews/2018/09/07/ntide-august-2018-jobs-report-returnto-positive-trend-for-employment-of-americans-withdisabilities

Broughton, A., \& Strebler, M. (2008). Reaping benefits from diversity. Strategic HR Review, 7(5), 5-10. https://doi.org/10.1108/14754390810893035

Carlson, D., \& Ehrlich, N. (2006). Sources of payment for assistive technology: Findings from a national survey of persons with disabilities. Assistive Technology, 18(1), 77-86. https://doi.org/10.1080/10400435.2006.10131908

Chan, F., Strauser, D., Maher, P., Lee, E. J., Jones, R., \& Johnson, E. T. (2010). Demand-side factors related to employment of people with disabilities: A survey of employers in the Midwest region of the United States. Journal of Occupational Rehabilitation, 20(4), 412-419. https://doi.org/10.1007/s10926-010-9252-6

De Stefano, F., Bagdadli, S., \& Camuffo, A. (2018). The HR role in corporate social responsibility and sustainability: A boundary-shifting literature review. Human Resource Management, 57(2), 549-566. https://doi.org/10.1002/hrm.21870

Erickson, W. A., von Schrader, S., Bruyère, S. M., \& VanLooy, S. A. (2014). The employment environment: Employer perspectives, policies, and practices regarding the employment of persons with disabilities. Rehabilitation Counseling Bulletin, 57(4), 195-208. https://doi.org/10.1177/0034355213509841

Fenwick, T., \& Bierema, L. (2008). Corporate social responsibility: Issues for human resource development professionals. International Journal of Training and Development, 12(1), 24-35. https://doi.org/10.1111/j.1468-2419.2007.00293.x

French, S. (1992). Simulation exercises in disability awareness training: A critique. Disability, Handicap \& Society, 7(3), 257266. https://doi.org/10.1080/02674649266780261

Gilbride, D., Stensrud, R., Vandergoot, D., \& Golden, K. (2003). Identification of the characteristics of work environments and employers open to hiring and accommodating people with disabilities. Rehabilitation Counseling Bulletin, 46(3), 130-137. https://doi.org/10.1177/00343552030460030101

Gould, R., Harris, S. P., Caldwell, K., Fujiura, G., Jones, R., Ojok, P., \& Enriquez, K. P. (2015). Beyond the law: A review of knowledge, attitudes and perceptions in ADA employment research. Disability Studies Quarterly, 35(3). http://dx.doi.org/10.18061/dsq.v35i3.4935

Hernandez, B., \& McDonald, K. (2010). Exploring the Costs and Benefits of Workers with Disabilities. Journal of Rehabilitation, 76(3).

Hernandez, C. A. (2018). Market Reactions to the Inclusion of People with Disabilities. Evidence for the Business Case. In Academy of Management Proceedings (Vol. 2018, No. 1, p. 18277). Briarcliff Manor, NY: Academy of Management. https://doi.org/10.5465/AMBPP.2018.18277abstract

Herring, C. (2009). Does diversity pay? Race, gender, and the business case for diversity. American Sociological Review, 74(2), 208-224. https://doi.org/10.1177/000312240907400203

Houtenville, A., \& Kalargyrou, V. (2015). Employers' perspectives about employing people with disabilities: A comparative study across industries. Cornell Hospitality Quarterly, 56(2), 168179. https://doi.org/10.1177/1938965514551633 
Kalargyrou, V. (2014). Gaining a competitive advantage with disability inclusion initiatives. Journal of Human Resources in Hospitality \& Tourism, 13(2), 120-145. https://doi.org/10.1080/15332845.2014.847300

Karpur, A., VanLooy, S. A., \& Bruyère, M. (2014). Employer practices for employment of people with disabilities: A literature scoping review. Rehabilitation Research, Policy, and Education, 28(4), 225-241. https://doi.org/10.1891/21686653.28.4.225

Kaye, H. S., Jans, L. H., \& Jones, E. C. (2011). Why don't employers hire and retain workers with disabilities? Journal of Occupational Rehabilitation, 21(4), 526-536. https://doi.org/10.1007/s10926-011-9302-8

Lengnick-Hall, M. L., Gaunt, P. M., \& Kulkarni, M. (2008). Overlooked and underutilized: People with disabilities are an untapped human resource. Human Resource Management, 47(2), 255-273. https://doi.org/10.1002/hrm.20211

Lieblich, A., Tuval-Mashiach, R., \& Zilber, T. (1998). Applied Social Research Methods: Narrative research. SAGE Publications, Inc. doi: 10.4135/9781412985253

Markel, K. S., \& Barclay, L. A. (2009). Addressing the underemployment of persons with disabilities: Recommendations for expanding organizational social responsibility. Employee Responsibilities and Rights Journal, 21(4), 305. doi: 10.1007/s10672-009-9125-3

Meena, K., \& Vanka, S. (2017). Developing an empirical typology of diversity-oriented human resource management practices. Journal of Management Development, 36(7), 915929. https://doi.org/10.1108/JMD-02-2016-0031

Moore, K., McDonald, P., \& Bartlett, J. (2017). The social legitimacy of disability inclusive human resource practices: The case of a large retail organisation. Human Resource Management Journal, 27(4), 514-529. https://doi.org/10.1111/17488583.12129

Office of Disability Employment Policy. (2015). Disability and employment: A timeline. Retrieved from https://www.dol.gov/featured/ada/timeline/alternative

Phillips, B. N., Deiches, J., Morrison, B., Chan, F., \& Bezyak, J. L. (2016). Disability diversity training in the workplace: Systematic review and future directions. Journal of Occupational Rehabilitation, 26(3), 264-275. https://doi.org/10.1007/s10926-015-9612-3

Phillips, B. N., Morrison, B., Deiches, J. F., Min-Chi Yan, Strauser, D., Fong Chan, \& Hyun-Ju Kang. (2016). Employer-driven disability services provided by a mediumsized information technology company: A qualitative case study. Journal of Vocational Rehabilitation, 45(1), 85-96. https://doi.org/10.3233/JVR-160813

Pichler, S., Blazovich, J. L., Cook, K. A., Huston, J. M., \& Strawser, W. R. (2018). Do LGBT-supportive corporate policies enhance firm performance? Human Resource Management, 57(1), 263278. https://doi.org/10.1002/hrm.21831
Robert, P. (2003). Disability oppression in the contemporary US capitalist workplace. Science \& Society, 67(2), 136-159. https://doi.org/10.1521/siso.67.2.136.21186

Robinson, G., \& Dechant, K. (1997). Building a business case for diversity. Academy of Management Perspectives, 11(3), 21-31.

Schein, E. H. (2010). Organizational culture and leadership (4th ed.). John Wiley \& Sons.

Schur, L., Kruse, D., \& Blanck, P. (2005). Corporate culture and the employment of persons with disabilities. Behavioral Sciences \& the Law, 23(1), 3-20. https://doi.org/10.1002/bsl.624

Schur, L., Nishii, L., Adya, M., Kruse, D., Bruyère, S. M., \& Blanck, P. (2014). Accommodating employees with and without disabilities. Human Resource Management, 53(4), 593-621. https://doi.org/10.1002/hrm.21607

Schur, L., Kruse, D., \& Blanck, P. (2013). People with disabilities: Sidelined or mainstreamed? Cambridge University Press.

Shore, L. M., Chung-Herrera, B. G., Dean, M. A., Ehrhart, K. H., Jung, D. I., Randel, A. E., \& Singh, G. (2009). Diversity in organizations: Where are we now and where are we going? Human Resource Management Review, 19(2), 117-133. https://doi.org/10.1016/j.hrmr.2008.10.004

Siperstein, G. N., Romano, N., Mohler, A., \& Parker, R. (2006). A national survey of consumer attitudes towards companies that hire people with disabilities. Journal of Vocational Rehabilitation, 24(1), 3-9.

Solovieva, T. I., Dowler, D. L., \& Walls, R. T. (2011). Employer benefits from making workplace accommodations. Disability and Health Journal, 4(1), 39-45. https://doi.org/10.1016/j.dhjo.2010.03.001

Theodorakopoulos, N., \& Budhwar, P. (2015). Guest Editors' Introduction: Diversity and Inclusion in Different Work Settings: Emerging Patterns, Challenges, and Research Agenda. Human Resource Management, 54(2), 177-197. https://doi.org/10.1002/hrm.21715

Worthington, I., Ram, M., Boyal, H., \& Shah, M. (2008). Researching the drivers of socially responsible purchasing: A cross-national study of supplier diversity initiatives. Journal of Business Ethics, 79(3), 319-331. https://doi.org/10.1007/s10551-007-9400-x

Yin, M., Shaewitz, D., Overton, C., and Smith, D. (2018). A hidden market: The purchasing power of working-age adults with disabilities. American Institutes for Research. Retrieved from https://www.air.org/resource/hidden-market-purchasingpower-working-age-adults-disabilities

Zola, I. K. (2005). Toward the necessary universalizing of a disability policy. The Milbank Quarterly, 83(4). https://doi.org/10.1111/j.1468-0009.2005.00436.x 
Appendix A

Company names, Year of Report, and title of report

\begin{tabular}{|c|c|c|}
\hline Company & Year & Report Title \\
\hline Aetna & 2015 & 2015 Corporate Social Responsibility Report \\
\hline Ameren & 2015 & 2015 Corporate Social Responsibility Report \\
\hline American Airlines & 2016 & 2016 Corporate Responsibility Report \\
\hline Anthem & 2016 & Diversity and Inclusion \\
\hline AT\&T & 2015 & Diversity and Inclusion 2015 Annual Report \\
\hline BAE Systems, Inc. & 2015 & Corporate Responsibility Summary 2015 \\
\hline Booz Allen Hamilton & 2016 & People, Purpose, Passion: Impact Report 2016 \\
\hline Boston Scientific Corporation & 2016 & $\begin{array}{l}2016 \text { Corporate Sustainability and Social Responsibility } \\
\text { Report }\end{array}$ \\
\hline Brown-Forman Corporation & $2015 / 2016$ & $\begin{array}{l}\text { Partners in Responsibility: Corporate Responsibility } \\
\text { Report }\end{array}$ \\
\hline Capital One & 2015 & $\begin{array}{l}\text { In Pursuit of the Greater Good: Corporate Social } \\
\text { Responsibility Report } 2015\end{array}$ \\
\hline Cigna & 2016 & Cigna Connects: 2016 Corporate Responsibility Report \\
\hline Comcast NBCUniversal & 2016 & $\begin{array}{l}\text { Our Foundation for Innovation: } 2016 \text { Diversity \& } \\
\text { Inclusion Report }\end{array}$ \\
\hline $\mathrm{CSC}$ & 2016 & $\begin{array}{l}2016 \text { Corporate Responsibility and Sustainability } \\
\text { Report: Leading for Success }\end{array}$ \\
\hline Delta Air Lines, Inc. & 2016 & $\begin{array}{l}\text { The World is Changed by Those in it: } 2016 \text { Corporate } \\
\text { Responsibility Report }\end{array}$ \\
\hline Ernst \& Young LLP & 2015 & $\begin{array}{l}\text { How do we all benefit from good citizenship? US } \\
\text { Sustainability Report } 2015\end{array}$ \\
\hline Florida Blue (BlueCross BlueShield of Florida) & 2016 & Many cultures, One goal, Your health: Diversity Report \\
\hline General Motors & 2016 & General Motors Diversity \& Inclusion \\
\hline Highmark Health & 2016 & $\begin{array}{l}\text { Diversity Inclusion, 2016, Annual Update: Being at } \\
\text { Highmark Health }\end{array}$ \\
\hline HP Inc. & 2015 & 2015 Sustainability Report \\
\hline KPMG LLP & 2016 & $\begin{array}{l}\text { Making a tangible difference: } 2016 \text { Corporate } \\
\text { Citizenship Report }\end{array}$ \\
\hline Lincoln Financial Group & 2016 & 2016 Corporate Social Responsibility \\
\hline Lockheed Martin & 2016 & 2016 Sustainability Report: The Science of Citizenship \\
\hline ManpowerGroup & 2016 & $\begin{array}{l}\text { Powering the World of Work, ManpowerGroup, Doing } \\
\text { Well By Doing Good: 2015/2016 Sustainability } \\
\text { Report }\end{array}$ \\
\hline Northrup Grumman Corporation & 2016 & 2016 Corporate Responsibility Report \\
\hline Pacific Gas and Electric Company & 2015 & $\begin{array}{l}\text { Corporate Responsibility and Sustainability Report } \\
\text { 2015: Together, Building a Better California }\end{array}$ \\
\hline PricewaterhouseCoopers & 2016 & Making a difference Global Annual Review 2016 \\
\hline Procter \& Gamble & 2015 & $\begin{array}{l}2015 \text { Diversity \& Inclusion Annual Report: Enabling a } \\
\text { Culture of Innovation \& Productivity }\end{array}$ \\
\hline Qualcomm Incorporated & 2016 & Qualcomm Sustainability Report \\
\hline TD Bank & 2016 & $\begin{array}{l}2016 \text { Corporate Responsibility Report: Enriching the } \\
\text { lives of our customers, communities and colleagues }\end{array}$ \\
\hline The Boeing Company & 2016 & Diversity and Inclusion \\
\hline United Airlines, Inc. & 2015 & 2015 Corporate Responsibility Report \\
\hline Verizon & 2016 & $\begin{array}{l}\text { A better future for everyone: } 2016 \text { Corporate } \\
\text { Responsibility Supplement }\end{array}$ \\
\hline Walmart & 2016 & 2016 Culture, Diversity \& Inclusion Report \\
\hline Wells Fargo \& Company & 2015 & $\begin{array}{l}\text { Corporate Social Responsibility Report 2015: Earning } \\
\text { lifelong relationships. Creating solutions for stronger } \\
\text { communities. }\end{array}$ \\
\hline
\end{tabular}

